\title{
Textural and Knowledge-based Lithological Classification of Remote Sensing Data in Southwestern Prieska Sub-basin, Transvaal Supergroup, South Africa
}

\author{
Na Li ${ }^{a}$, Michaela Frei ${ }^{b}$, Wladyslaw Altermann ${ }^{\text {b }}$ \\ ${ }^{a}$ Dept. Earth \& Environmental Sci. LMU, München, Germany \\ ${ }^{b}$ Dept. of Geology, University of Pretoria
}

\begin{abstract}
TM data and other medium spatial resolution satellite data are used in geological and lithologicalmineralogical classification on regular basis, although their usefulness is limited because of relatively coarse spectral resolution. In this contribution, we provide an example for the application of TM data for classification of rocks and minerals within the Neoarchean sedimentary and volcanic basin of Griqualand West, South Africa. An improved methodology is introduced that results in significantly higher classification accuracy. The TM multispectral image and Principal Component analysis (PCA) image of the test area were individually combined with textural features and then classified individually using a Maximum-Likelihood supervised classification (MLC). Subsequently, the two classified images were integrated, compared and re-classified in a knowledge-based system (KBS) using the generalized supplementary geological map on 1:250000 scale. With this method, the accuracy was improved from $54.3 \%$ to $83.2 \%$, when compared to the former supervised classification. The method integrates the spectral and textural features, greatly contributing to the precision of the lithological classification, mapping and prospecting, in extensive areas where field work is limited by time and cost constrains.
\end{abstract}


Keywords: Remote sensing; Thematic Mapper, lithological/ mineralogical classification; textural features; knowledge-based system; mapping; Griqualand West; Transvaal Supergroup; BIF; carbonates

\section{Introduction}

Geological remote sensing by multi-spectral satellite imagery is based on differences in physical and chemical properties of all rock types. Through these disparities, different rock types reflect electromagnetic energy in different ways, permitting for identification of unique or typical spectral characteristics of the rock mineralogy. In addition to the spectral features, textural features of the rocks, influenced by e.g. weathering (and thus also indirectly reflecting physical and chemical properties), erosion and drainage pattern, provide useful supporting information to distinguish rock types. The globally available satellite images, such as the Landsat Thematic Mapper (TM) imagery, are widely used in classification processes, with the purpose of generating lithological maps and detecting mineral anomalies, mostly in arid and semiarid regions.

Factors like the only moderate spatial resolution of $30 \mathrm{~m}$ and the low spectral resolution in seven bands only, limit the usefulness and classification accuracy of Landsat TM image data, when based solely on spectral bands. Moreover, lithological boundaries are not necessarily distinct and sharp and can be obscured by scree and other deposits. In addition to that different kinds of rock types may show analogous spectral characteristics, resulting in spectral overlap and misclassification. Thus, many advanced classification approaches have been put forward in the general remote sensing literature, to improve the classification accuracy. For example, textural features, as proposed above, were used to improve the urban areas and land cover classification (Shaban and Dikshit, 2001; Rao et al., 2002; Chen et al., 2004); e.g. the artificial neural networks (ANN) was efficiently used in land cover classification (Kavzoglu and Mather, 2003); "fuzzy classification" was efficient in decreasing the mix-pixel problem (Shalan et al., 2003), and the knowledge-based system (KBS), especially, incorporating GIS, 
plays an important role because it is capable of managing different sources of data (Stefanov, 2001; Daniels, 2006; Lu and Weng, 2006; Alaaddin, 2008).

The principal component analysis (PCA) is widely used in geology (Loughlin, 1991) as an image processing approach. The first component encompasses the brightness information, sometimes called albedo. The second and all other subsequent principal components encompass divergences in spectral reflectance among surface materials which depend on their mineralogical-chemical characteristics and other properties, such as e.g. surface roughness. Conventionally principal components 1, 2, 3 are displayed as RGB (red, green, blue) composite, because the first three components carry most of the information. In this contribution, the components 4, 3, 2 were combined in RGB, because with this combination, different geological features appear better noticeable in different colours and thus, show better differentiation.

One of the major visual properties of rocks is their texture, which is important in image interpretation. The textural features of the various rock types are influenced by many factors. For example, the same rock type may show different texture features because of its different surrounding environment or different structural history, dip angle and outcrop conditions. Therefore, it should be assumed that textural parameters can also assist in rock type discrimination and classification. Among many textural measures that have been developed, the grey-level co-occurrence matrix (GLCM)-based analysis and geostatistical-based analysis are used most commonly in classification improvement. Some researchers compared these two methods and then used the superior one (Lloyd et al., 2003; Zhang et al., 2003), but seldom research in combining these two methods.

In the study area in South Africa, Griqualand West, the only official geological map available is one at a coarse scale of 1:250000 (Council for Geosciences, 1995) which is not nearly elaborate enough for detailed planning. For ongoing prospect campaigns maps of a scale of 1:100.000 or larger are necessary. Therefore, the use of TM imagery, supported by 
ancillary data sets is the common solution for geologists, despite their limited spatial resolution.

To overcome this constraint, the approach presented here, uses GLCM textural features, plus geostatistical textural features separated from the original spectral bands and principle components. Both were mathematically combined and incorporated into the maximumlikelihood supervised classification (MLC). The results were subsequently incorporated into a knowledge-based system (KBS), where the different classified images were compared and reclassified, according to the criterions extracted from the interpretation of the TM image and the analysis of the existing digital geological map. The resulting classification will be used for compiling lithological maps based on remote sensing data and ground controlling. The area was selected as test site for the newly defined classification algorithm due to its wide range of different lithological units, due to the intensive field knowledge and availability of existing maps in various scales and its mineral potential.

\section{Study area}

The Griqualand West sub-basin of the Transvaal Supergroup is one of the three Neoarchean to Paleoproterozoic structural basins on the Kaapvaal Craton of Southern Africa. The other sub-basins are the Transvaal sub-basin in South Africa and the Kanye sub-basin in Botswana. The Griqualand west sub- basin can be further subdivided into the Ghaap Plateau and the Prieska compartments. Both compartments are thought to be separated by a NW-SE trending fault zone (Griquatown Fault Zone; GFZ). They display similar, but not identical lithological successions of partly differing ages in their lower stratigraphic levels, and have a different mineral potential (Altermann, 1996; Altermann and Nelson, 1998). The northern Ghaap Plateau basin compartment supplies the world with giant iron and manganese deposits. The mineral potential of the southern, Prieska, basin compartment, has not been yet fully 
recognized, although the world's largest blue asbestos (crocidolite) deposits were mined here in the past.

The study area (Fig. 1) is located in the southwest of the Griqualand West Basin, in the Prieska compartment, between Westerberg and Prieska. The oldest rocks in the area consist of granitic basement comprising various intrusive bodies ranging down to $2.9 \mathrm{Ga}$. These are covered with an angular unconformity by the $2.7 \mathrm{Ga}$ basaltic - andesitic, partly porphyritic lavas of the Ventersdorp Supergroup. The Transvaal Supergroup follows unconformably on the lavas with a lacuna of at least 50 million years (Eriksson et al. 2006). It commences with quartzites and lavas (2.64 Ga, Walraven and Martini, 1995; Altermann, 1996), shales, carbonates and two successive banded iron formations (BIF). These are the Kuruman BIF (KBIF) and the Griquatown BIF (G-BIF), of Neoarchean to Paleoproterozoic age, and without noticeable unconformities (Beukes, 1986). The carbonates and banded iron formations (BIF) are intercalated with relatively thin but regionally extensive and uniform tuff beds. The Mesoto Neoproterozoic are not preserved in the study area; the sedimentary record only recommences with the upper Paleozoic (Permo-Carboniferous) glacial Dwyka deposits (Visser, 1989), followed by Mesozoic Karoo rocks (not preserved in the study area, apart from occasional intrusive dikes). Tertiary to Recent sands and alluvial and fluvial sand deposits cover the Precambrian and Paleozoic rocks. A Proterozoic diabase sill of regional extend intruded into the Neorchean and Paleoproterozoic rocks has been folded with the strata (Altermann and Hälbich, 1990; 1991). The relatively less extensive, Mesozoic Karoo dikes are not folded and follow straight lineaments, which are well visible on satellite images but difficult to find in the field due to the alluvial cover. Both dike generations and the tuffs intercalated with the Neoarchean stromatolitic carbonates, display a similar, near basaltic composition (Altermann, 1997), but are genetically not related to each other. Rare and small Proterozoic syenite intrusions, presumably of $1.1 \mathrm{Ga}$, are scattered throughout the area. 


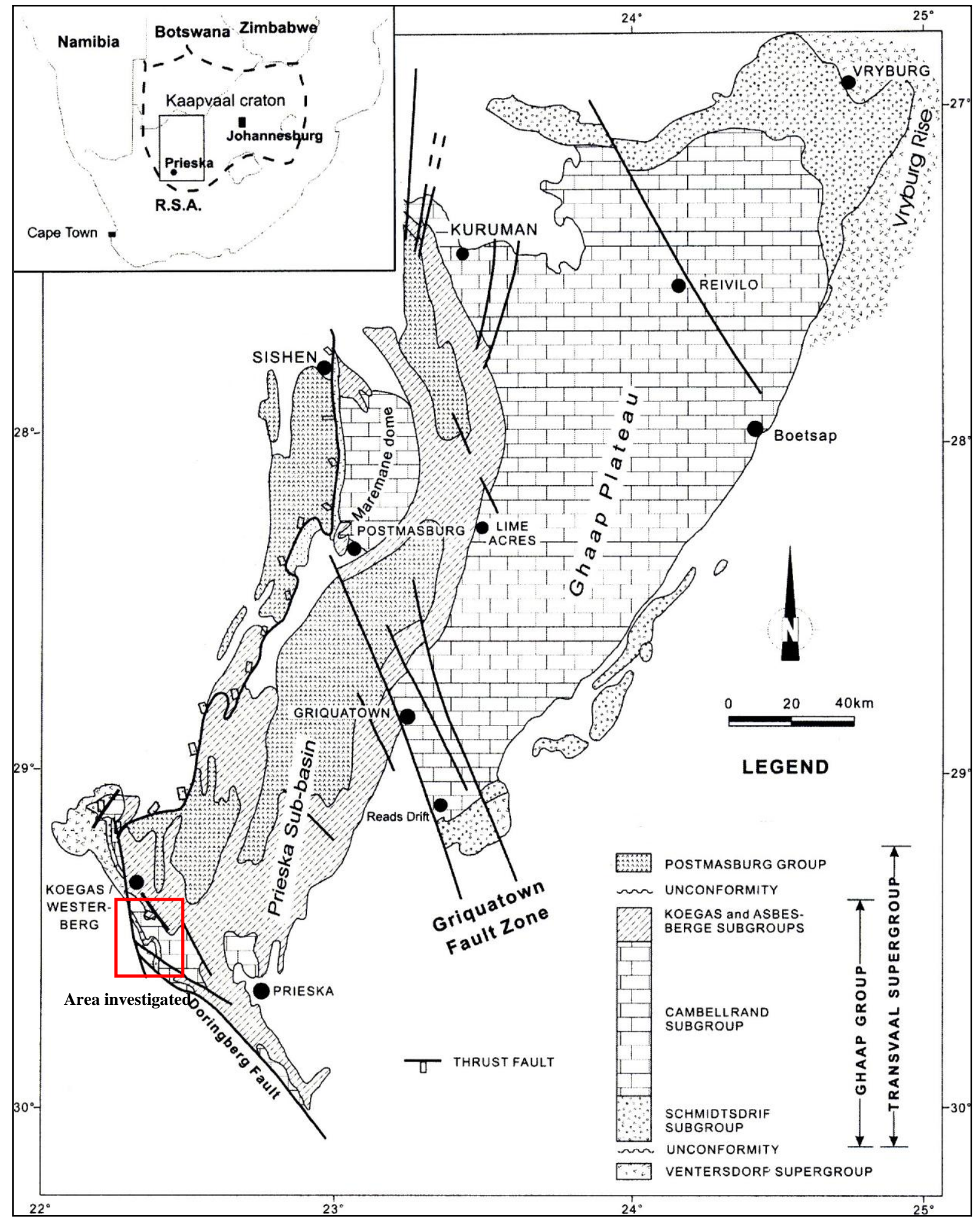

Fig. 1: Geological overview map of the study area at the south-western margin of the Kaapvaal Craton, Transvaal Supergroup. The test area used for the classification is indicated. 
The outcropping Neoarchean and Paleoproterozoic rocks have been extensively deformed during several events, encompassing up to seven phases between $>2.5 \mathrm{Ga}$ and $1.1 \mathrm{Ga}$ (Altermann and Hälbich, 1991). The circa NW-SE striking Doringberg Fault crosses the area under investigation and marks the youngest deformation event of c. $1.1 \mathrm{Ga}$. In the area between Prieska, Westerberg and Griquatown, stacking of thrust packages, particularly in the banded iron formations, affected the stratigraphy and thickness of various formations. Large and small scale folds and cleavage are, however developed in all Precambrian rocks (Altermann and Hälbich, 1991). The metamorphic grade in the Precambrian southwestern Griqualand West Basin, as reflected by metamorphic petrology and illite crystallinity, decreases from low to very low grade, approximately from west to east (Altermann, 1997).

The ground cover percentage of the Karoo vegetation in this arid area, with mean annual rainfall of less than $200 \mathrm{~mm}$ per year, strongly varies between the seasons, but is usually far below $20 \%$ except of a narrow belt of gallery forests along the Orange River, where it can be very dense during the length of the year.

\section{Material and methods}

A small test area of about $185 \mathrm{~km}^{2}$, of which the northern boundary coincides with the southern banks of the Orange River in Griqualand (Fig. 1) was selected as test area. Here, detailed field work has already been carried out between 2000 and 2005 by a large group of students (Frei and Altermann, 2006). A GIS -based geological map at a scale of 1:25000 was compiled by Glas (2008) from these data. This detailed map was later used to assess the classification accuracy. As soon as the accuracy was high enough, the proposed classification method was used to classify the entire study area.

Beside the pre-processing procedures (geometric and radiometric corrections) and Maximum-Likelihood supervised classification (MLC) (Li et al., 2009), textural analysis was 
performed in this research. The textural features were incorporated into MLC as extra bands and contributed significantly to improve the classification accuracy.

\subsection{Data preparation}

The Landsat TM data (Path/Row $179 / 80+81)$ of the study area were acquired on $26^{\text {th }}$, May, 1984, when the rainfall had been so little throughout the period before the data acquisition that the influence of vegetation cover can be disregarded. An ETM+ image from 2000 and the Geological Map at the scale of 1:250000 (Council for Geosciences, 1995) were also available. The ETM image contains record noise but it is rectified to UTM projection using the WGS 84 ellipsoid. The rectified ETM data set was used as basic data to rectify the TM data and the scanned geological map (Council for Geosciences, 1995). According to the algorithm optimum index factor (OIF) (Chavez et al., 1984), bands 7, 4, and 1 of the available TM image were combined in RGB, and then atmospheric correction was performed over the shadowed areas by a linear regression (Kaufman and Sendra, 1988). The data set was then rectified using a second order polynomial model and at least 6 ground control points (GCP) (Leica Geosystems, 2003), resulting in an overall RMS error of less than 1 pixel and check points error of less than 0.5 pixels. The RMS error is defined as the distance between the desired output coordinate for a GCP and the actual output coordinate for the same point, when the point was transformed with the geometric transformation model. The geological map 1:250000 was rectified in the same way, but using a first-order polynomial nearest-neighbour transformation and re-projected into the UTM projection zone 34 (WGS 84). The rectified TM image of the test area is shown in Figure 2(a).

In order to highlight geological features, such as the Banded Iron Formation (BIF), principal component analysis (PCA) was conducted, based on the input of all reflective channels of the TM data set and output of the first six components (PC 7 almost entirely 

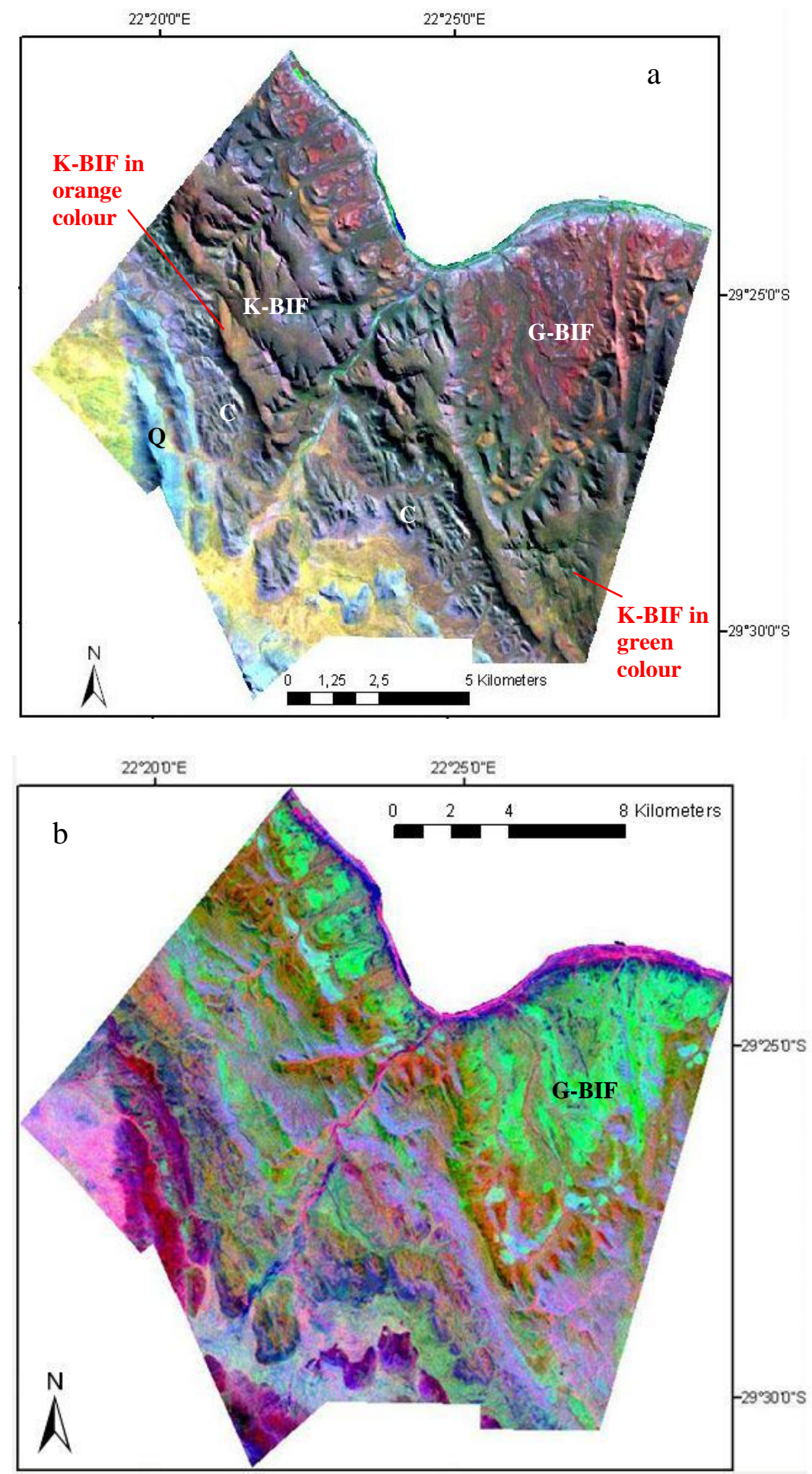

Fig.2.: (a) is a TM colour composite (bands7, 4, 1 as RGB), (b) is a PCA composite (PC4, PC3, PC2 as RGB).

In image (a) K-BIF outcrops appear in dark brown to dark red colours, occupying large areas. G-BIF appears red; carbonate (C) appears cyan, with a NW-SE texture; quartzite (Q) show in clear blue colours. In image (b) G-BIF outcrops exhibit in eye-catching green colours. 
consist of noise), then principal components 4, 3, 2 were combined in RGB (Fig 2 (b)). The existing 250.000 geological map (Council for Geosciences, 1995) was digitized. Different ID values were allocated to the different rock types, to be used as ancillary data in KBS. All the processing was supported by the software ERDAS IMAGINE $9.3^{\odot}$ and ArcGIS $9.2^{\odot}$.

The investigated area is well known for its occurrence of ferrous carbonate rocks and overlying iron formations, the lower of which being the chemically precipitated Kuruman Banded Iron Formation (K-BIF), and the upper one, the resedimented, granular Griquatown Banded Iron Formation (G-BIF) (Beukes, 1986). The combination of the multispectral TM image (Fig. 2(a)) and the geological map, allows the interpretation that K-BIF and G-BIF occupy most of the test area, followed by BIF footwall carbonates, and shales and quartzites below the carbonates. The K-BIF outcrops in most parts of the study area are large blocks in dark red or brown colour. The G-BIF appears in clear red-pink colour (Fig. 2(a)). The quartzite $(\mathrm{Q})$ appears in light blue and the carbonates $(\mathrm{C})$ in blue-green colour. In the PCA image (Fig. 2(b)), the G-BIF is represented in distinct green colour, while the quartzites and the aeolian quartz sands appear in red and pink colours respectively.

\subsection{Maximum-Likelihood supervised classification (MLC)}

In a supervised classification, spectral signatures are calculated from specified training sites in the image, by defining various polygons representing different rock types. The spectral signatures are then used to classify all pixels in the scene. Specific signature polygons were defined separately from the reflectance data in the multispectral image and in the PCA composite. Maximum- likelihood classification (MLC) was then preformed for each data set individually. Then post-classification analysis was carried out in order to re-code the class values of each rock type, using the lithological IDs derived from the geological map. This procedure ensured that the same IDs are allocated to the respective rock types in the two 
classification results, as in the digital geological map 1:250000 (Council for Geosciences, 1995). Pixels covered by shadow in both images were treated as an exception and omitted from this ID process, for lack of correlation with the geological map (1:250000).

Classification results of both data sets were compared to the detailed field geological map (Glas, 2008). 256 test points were picked randomly in the two classified images and the reference map. The accuracy reports were created by comparing the random point's class values in classified images with their values in the reference map. The data processing was carried out using the ERDAS IMAGINE $9.3^{\circledR}$.

\subsection{Textural analysis}

Texture is defined as the combination of the magnitude and frequency of tonal change on an image. It is produced by the aggregate effect of all of the many small features that make up a particular area of surface. Textural features of rock outcrops, caused by e.g. drainage, erosion, or weathering, provide useful supporting information to distinguish rock types, and can be incorporated to assist the classification. For example, carbonates in the study area exhibit a coarse NW-SE texture, while K-BIF outcrops have a relatively smooth texture. Discussed below are two of the most widely used methods to perform the textural analysis.

\subsubsection{Grey-level co-occurrence matrix (GLCM)-based texture analysis}

The grey-level co-occurrence matrix (Haralick, 1979), also known as grey-level spatial dependence matrix, is by far the most widely used approach in remote sensing, for the computation of second order textural features. Each element of the matrix $P(i, j)$ represents the "number" of occurrences of the pair of grey-levels $i$ and $j$, which are a distance $d$ (offset) apart in the original image. Several textural features can then be derived from this matrix. That is to say, the "number" in a fixed window is calculated from the pixel values in the 
original image to form the matrix, after which the central pixel value in the window is replaced by the textural feature value derived from this matrix. The window is then moved across the entire image, pixel by pixel and line by line.

Previous research shows that a small size of the moving window is preferable in analyzing the textural features of coarse resolution images (Shaban, and Dikshit, 2001; Chen, et al., 2004). Therefore, for all seven, most popular (Rao et al., 2002) textural features which were tested and applied in this contribution, a moving window of $3 * 3$ pixels was used. These seven textural parameters are defined as follows: $\mathrm{N}$ is the number of pixels in a moving window, e.g. for a $3 * 3$ window, $\mathrm{N}$ is 9 .

(a) Mean

$$
\text { Mean }=\sum_{i, j=0}^{N-1} i P(i, j)
$$

The Mean is an indicator of the distribution of grey levels.

(b) Standard deviation

$$
\text { St-de }=\sqrt{\frac{1}{N} \sum_{i, j=0}^{N-1}(\text { Mean }-P(i, j))^{2}}
$$

The Standard deviation denotes the dispersion of grey levels as defined by the sum of the squares. Generally, coarse - textured features are associated with higher standard deviations.

(c) Entropy

$$
\text { Entropy }=\sum_{i, j=0}^{N-1} P(i, j) \log (P(i, j))
$$

Entropy measures the disorder of an image. With increasing textural variability of the image, the GLCM element values become very low, and the entropy becomes very high.

(d) Contrast 


$$
\text { Contrast }=\sum_{i, j=0}^{N-1}(i-j)^{2} P(i, j)
$$

The Contrast measures the amount of local variances in an image, which represent the difference between the highest and the lowest values of a contiguous set of pixels. This means that high contrast values imply a highly coarse texture.

(e) Correlation

$$
\text { Correlation }=\sum_{i, j=0}^{N-1} \frac{(i-\mu)(j-\mu) P(i, j)}{\sigma_{i} \sigma_{j}}
$$

Hereby, $\mu$ is the mean and $\sigma$ is the standard deviation. Correlation is a measure of grey tone linear dependencies in the image. High correlation values imply a linear relationship between the grey levels of pixel pairs.

(f) Energy

$$
\text { Energy }=\sum_{i, j=0}^{N-1} P(i, j)^{2}
$$

Energy, or in other terms, the "Angular Second Moment" or "Uniformity", is a measure of the textural uniformity of an image, i.e., pixel pair repetition. The energy is high when grey value distribution has a constant or periodic form.

(g) Homogeneity

$$
\text { Homogeneity }=\sum_{i, j=0}^{N-1} \frac{P(i, j)}{1+|i-j|}
$$

Homogeneity, also known as "Inverse Difference Moment, assumes higher values for smaller grey tone differences in pixel pair elements.

The computation of GLCM is mainly based on a single band; in this study TM band 5 was selected because of its high standard deviation. From band 5 displayed as grey- scale image, test sites were selected which represent the five main different rock types (examples listed in Fig. 3). Based on these sample sites, the GLCM values were computed and 7 features were 

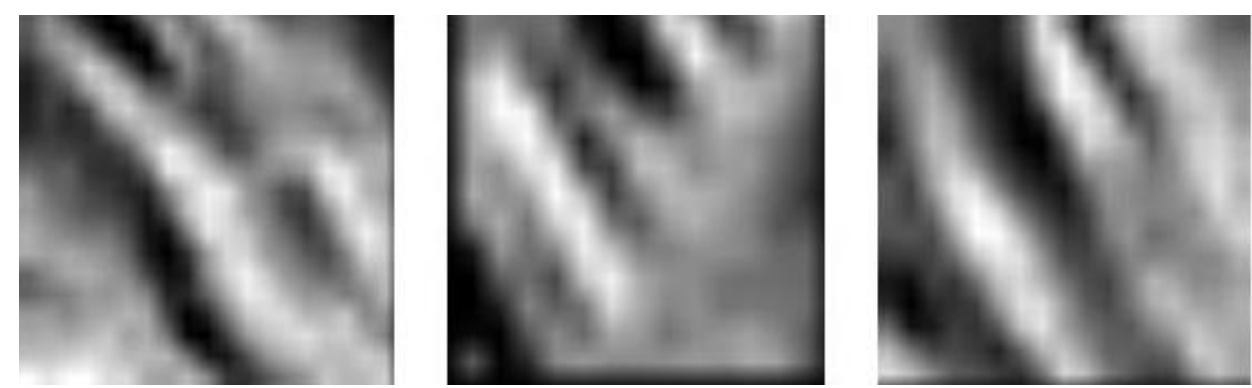

(a) Texture samples of carbonate covered area

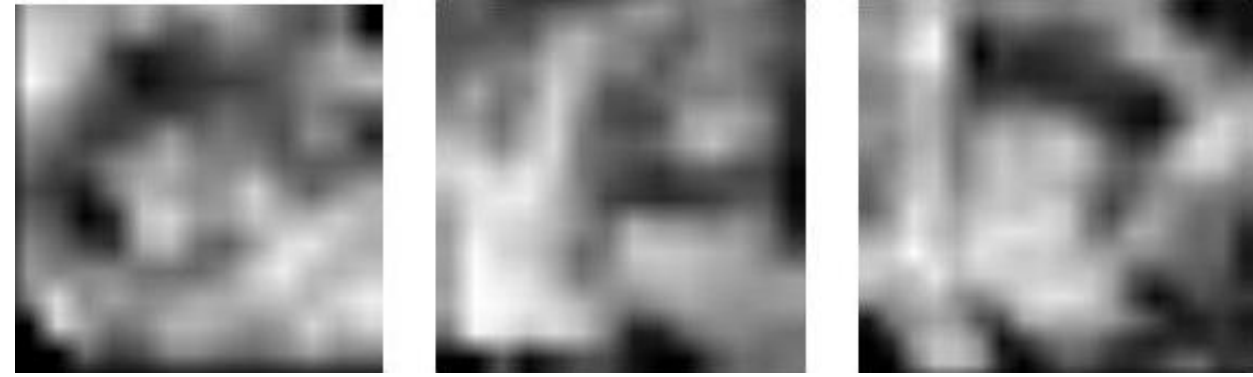

(b) Texture samples of Griquatown BIF (G-BIF) covered area
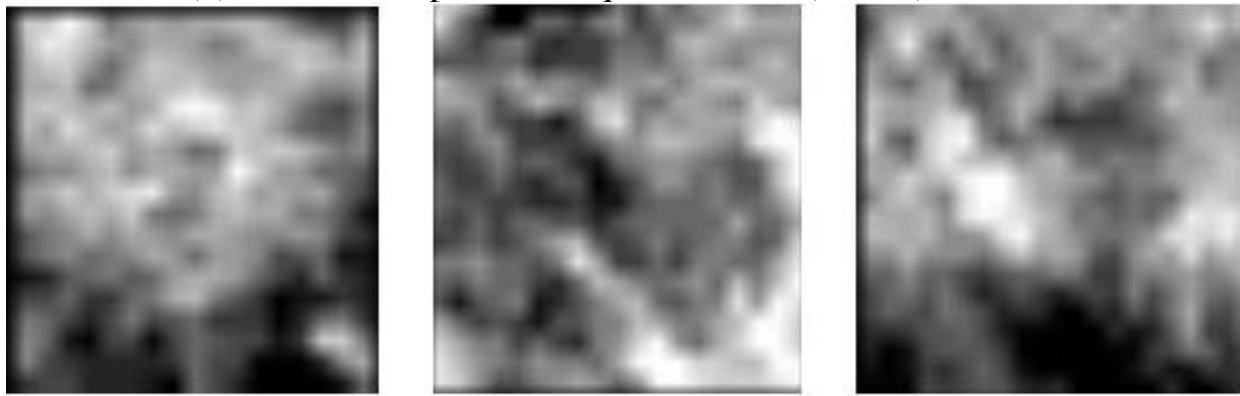

(c) Texture samples of Kuruman BIF (K-BIF) covered area
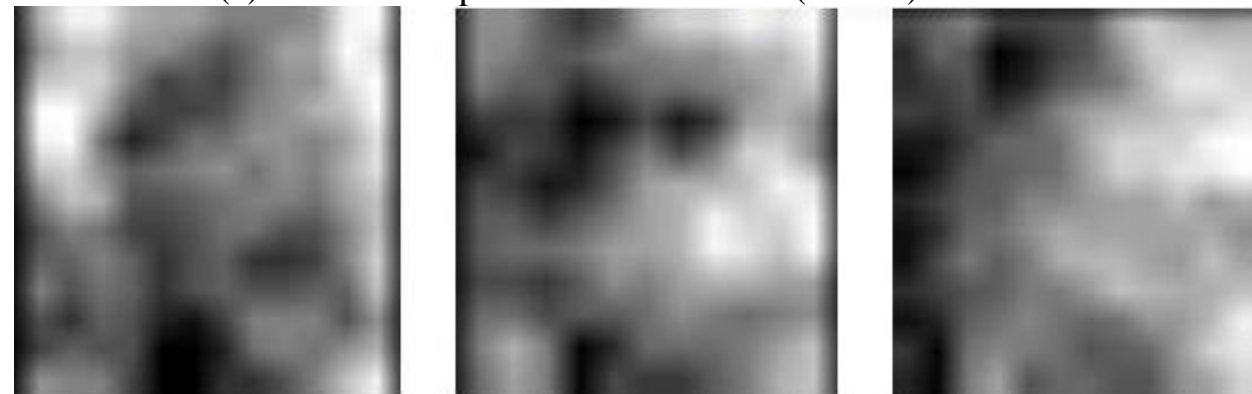

d) Texture samples of (Schmidtsdrif Subgroup) quartzite covered area
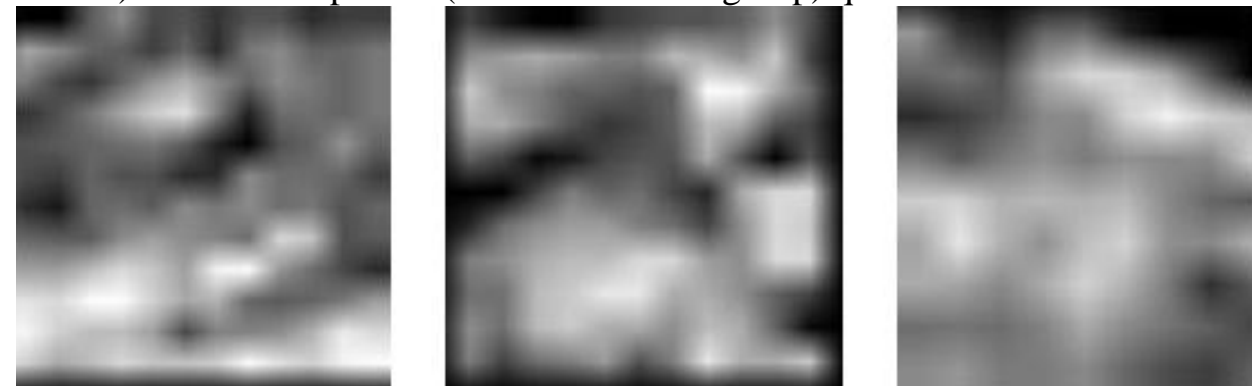

e) Texture samples of fluvial sand

Fig. 3: (a) Texture samples of carbonate rocks show clear NW-SE trending linear patterns where black and pale grey values alternate. The texture of the Kuruman BIF in (c) is much more heterogeneous and clearly less linear, but a weak NW-SE trend is still recognizable, compared to the textures in (b) (d) and (e), which are all visually similar. Each square covers an area of $570 * 570 \mathrm{~m}$. 
derived separately, with offset values of 1 and 5 respectively. For each sample site, the average value GLCM for four directions (N-S, E-W, N45 $\left.{ }^{\circ} \mathrm{E}, \mathrm{N} 45^{\circ} \mathrm{W}\right)$ was calculated. For each specific rock type the average value for each textural feature was calculated, based on all sample sites. All textural feature values were normalized between 0 and 1 for comparison (Fig. 4).

Figure 4 shows that the seven different textural statistics values behave differently for different rock types. The following three texture features, 'st-de' and 'homogeneity' at $\mathrm{d}=1$ and 'contrast' at $\mathrm{d}=5$, were selected as they turned out to be most efficient to differentiate the rock types. Due to the coarse spatial resolution of the image, a moving window not larger than $3 * 3$ pixels was used to compute these three textural features (Chen et al., 2004).

When $d=1$, five main lithology types could be separated when analyzing the differences for the X values for "mean", "st-de", "correlation" and "homogeneity". However, the Y values for "mean" and "correlation", were too closely spaced to be usable for discrimination. Hence, "st-de" and "homogeneity" proved to be more suitable parameters for discriminating between different rock types. For $\mathrm{d}=5$, the most suitable textural feature for lithological discrimination was "contrast" (Fig. 4). From these textural features, namely "st-de", "correlation" and "contrast", three GLCM textural bands were derived and used for further analysis (see below).

\subsubsection{Geostatistic-based texture analysis}

Geostatistical methods are used increasingly in remote sensing, in order to both characterize the spatial correlation and to improve classification accuracy (Jakomulska and Stawiecka, 2002). The geostatistical approach implies that each pixel of the image has two characters: local variability and spatial regularity (Figure 5). This means that the values for the nested pixel values are variable on local scale, but, at the same time, show regularity on 

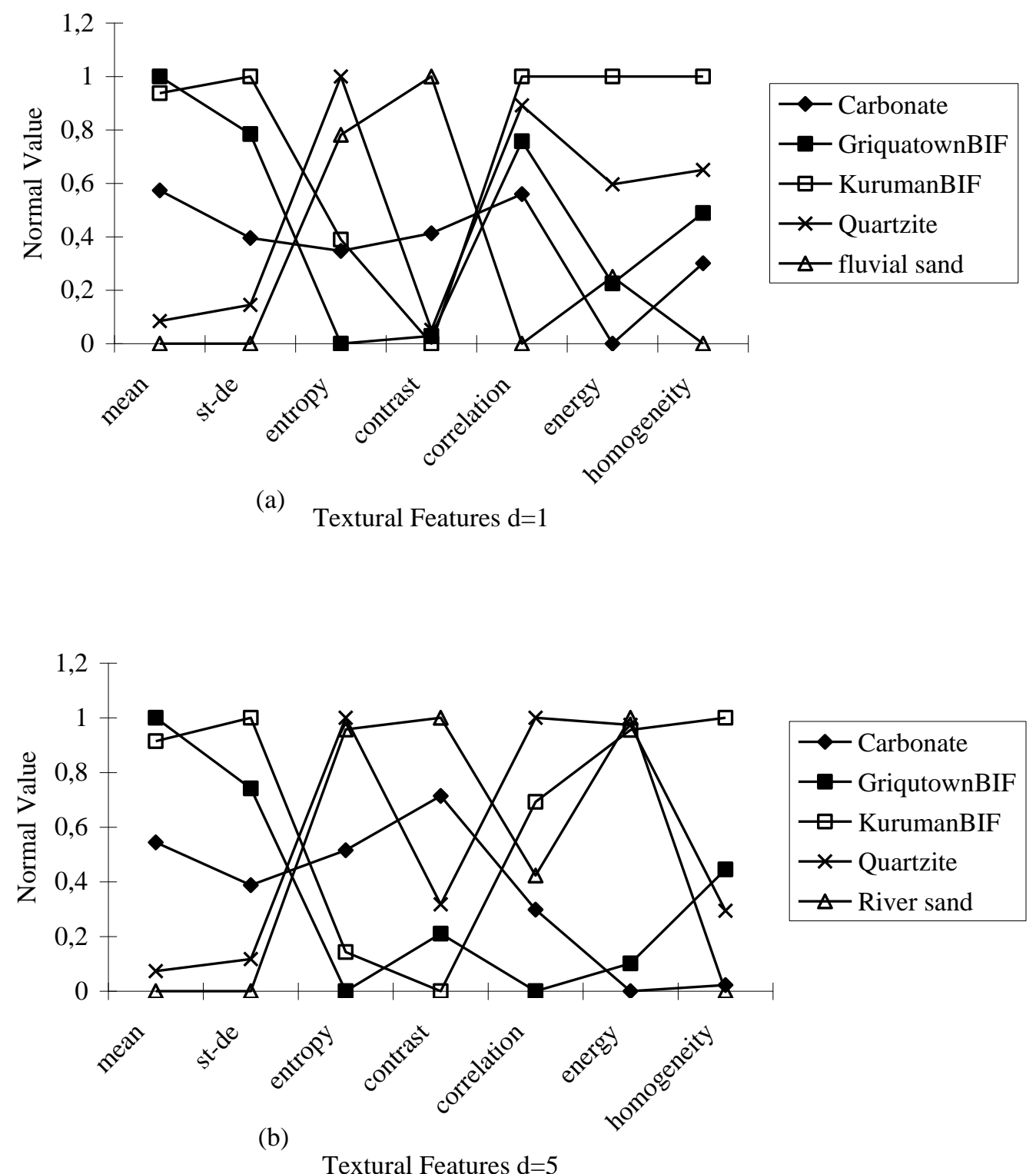

Fig. 4: Capability of different textural features, to discriminate between different rock types when $d=1$ (a) and $d=5$ (b). The $X$ axis represents different textural features. The $Y$ axis shows the normal value (between 0 and 1). For each textural feature, a large difference of the normal values between two rock types indicates a high probability to discriminate between them. For example, the normal values of the recent fluvial sand and Archean carbonate in "mean" are sufficiently far apart from each other, so they can be discriminated well using the "mean", but for Griquatown BIF and Kuruman BIF, their normal values in "mean" are too close to each other, to be differentiated. 


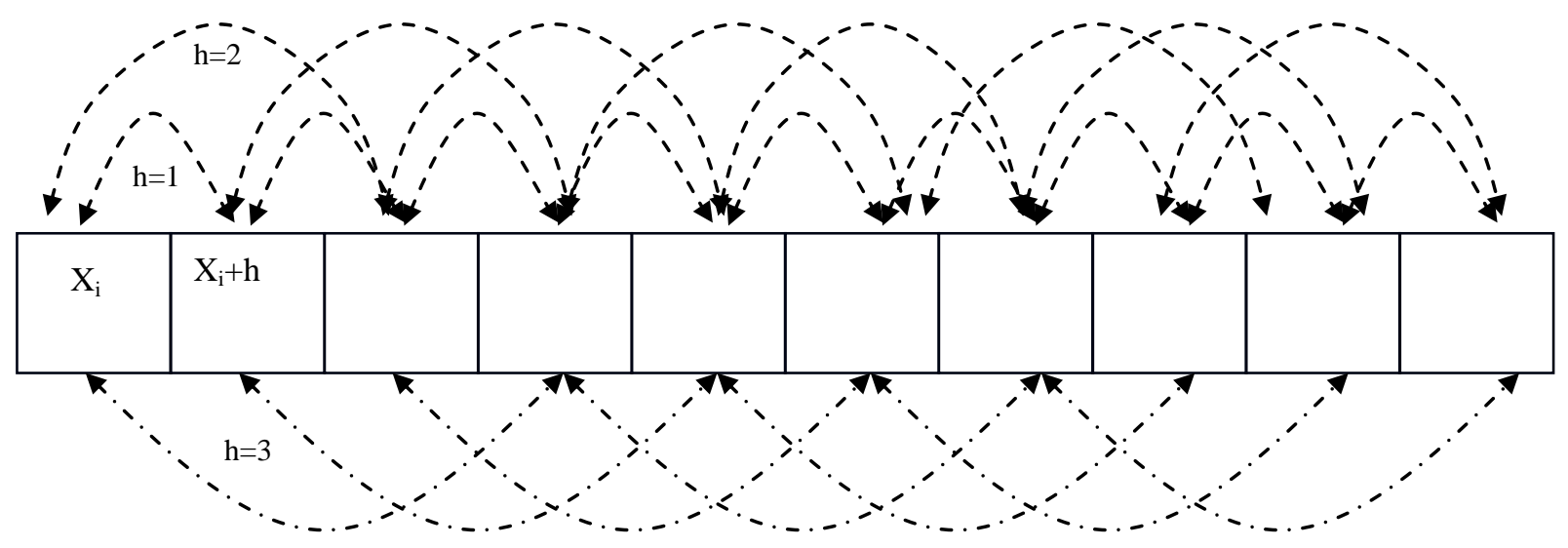

Fig. 5: The principle of variogram calculation between nested pixels. " $h$ " is the distance between nested pixels. The detailed equation is discussed in section 3 . 
large spatial scale. Fig. 5 is an illustration of the variogram calculation between nested pixels, while the equitation below illustrates the mathematical combination of these two characters.

$$
\text { Variogram r }(\mathrm{h})=\frac{1}{2 N(h)} \sum_{i=1}^{N(h)}\left(D N\left(X_{i}\right)-D N\left(X_{i}+h\right)\right)^{2}
$$

$\mathrm{N}(\mathrm{h})$ : the number of the pixels in moving window

h: (lag interval) the distance between nested pixels

Since textural analyses are often based on single bands only, and since only one geostatistical feature can be derived from one band (Chica-Olmo and Abarca-Hernandez, 2000), in this contribution, six geostatistical parameters were calculated separately from six TM bands (bands 1-5 and 7), plus three additional geostatistical features from the three

principle components 1,2 and 3. As with the textural features described in 3.3.1, again average values were calculated for four directions (N-S, E-W, N45 $\left.\mathrm{E}, \mathrm{N} 45^{\circ} \mathrm{W}\right)$ to show textural characteristics (Shaban and Dikshit, 2001).

All textural calculations described in Section 3.3 were performed using the software Matlab $7^{\circledR}$

\section{Application of textural analysis to the TM data}

\subsection{MLC based on the combination of spectral features}

All these textural analysis resulted in a total of three GLCM bands and nine geostatistic textural bands (six from the six TM bands, three more from the three PC bands).

As a next step, the original PCA bands were stacked with the three calculated GLCM texture bands, to generate a 9-band image which was named PCA-GLCM . Also the six PCA bands were combined with those three geostatistic textural bands, which had been derived 
from PC 1, 2 and 3, in order to produce a second 9-band image, which was named PCA-GEO respectively.

The original 6-band TM image (bands 1-5 and 7) was combined with three GLCM texture bands to generate a third 9-band image, which was named TM-GLCM. Similarly, the six original TM bands were also combined with those six geostatistic texture bands, which have been derived from the six TM bands, which resulted in a new 12-band image, named TM-GEO.

For each of these four new images (PCA-GLCM, PCA-GEO, TM-GLCM, TM-GEO), separate Maximum-Likelihood-Classification (MLC) was carried out. This was followed by post-classification which incorporated the ID values from the existing digital geological map (same steps as described in Section 3.2) and recoded the class values, in order to have corresponding values between classification results.

\subsection{Knowledge-based classification (KBS)}

A knowledge-based system algorithm was used, in order to reclassify pixels, which were misclassified in previous classification attempts, and to improve the overall classification accuracy. This included correction factors derived from the digitized geological maps as well as from visual image interpretation.

Disregarding the problem of mixed pixel for now, each object in the field, as represented by one specific pixel, should ideally be classifiable into one of the pre-defined classes of rock types. Hence, in two classification results of the same area, corresponding pixels of the same position should belong to the same lithology class after the above described re-coding.

However, this was not the case. The discrepancies were partly caused by the different spectral band combinations (original, or PC) used for classification, which highlight different rock properties. On the other hand, the limited spatial and spectral resolution of the TM data, 
wavelength which leads to misclassification of pixels, due to the mixed-pixel problem also resulted in discrepancies. Such mismatching pixels were investigated in more detail, to analyze the cause for the misclassification. Some of the corresponding pixels which had identical (geological) class ID values were considered to have a low risk of misclassification, and were named "consistent pixels". Other corresponding pixels, however, of different class ID values, were therefore at a high risk of being misclassified, and named "inconsistent pixels", accordingly.

An algorithm was designed to preserve the class ID values of the "consistent pixels" and simultaneously to pick out the "inconsistent pixels" by marking them with the class ID value 1 , the same class value as shadow pixels. The class ID values of the consistent pixels were kept unchanged in the KBS, ensuring that the accuracy of the reclassified image can not be lower than that from the traditional maximum likelihood classification solely.

The inconsistent pixels (class value $=1$ ), the shadow pixels (class value $=1$ ) and the unclassified pixels (class value $=0$ ) were reclassified simultaneously in the KBS, using the geological map 1: 250000 (Council for Geosciences, 1995). A new algorithm was designed and applied, in order to replace those pixels with values 0 or 1 , with the ID values from the geological map. Both new algorithms were implemented in the 'Spatial Modeler' of the ERDAS IMAGINE ${ }^{\odot}$ software package

\section{Results and discussion}

\subsection{Supervised Maximum-Likelihood classification (MLC)}

Table 1 shows the classification accuracy and Kappa coefficient of six images. The Kappa coefficient expresses the percentage of error reduction through a supervised classification process, as compared to the classification accuracy of a completely random classification. For 
example, a value of 0.82 means that through classification process $82 \%$ of the errors were avoided, which a completely random classification would have generated (Congalton, 1991).

The textural feature-combined images (3 thru 6) have a higher classification accuracy compared to the original images consisting of six TM bands or three PCA bands only. This shows that textural features can complement the classification well. As shown in Fig. 3a, carbonate outcrops have a distinct NW-SE trending directional texture, but the river sand (Fig. 3e) does not. K-BIF outcrops (Fig. 3c) show homogeneous texture, but G-BIF (Fig.3b) exhibit a relatively heterogeneous texture. In spite of these clear textural differences, when using the TM bands alone, misclassification of pixels was unavoidable, especially for pixels located near the border between two different rock types, e.g., pixels near the outcrop border between K-BIF and carbonate rocks, or near the border between K-BIF and diabase dikes. Another reason for misclassification is the spectral similarity between diverging lithologies, such as between the river sand and carbonate rocks, calcrete and some talus material deposits. Even more so, for the chemically-mineralogically almost identical BIF misclassification occurs. In the classified PCA image, G-BIF can be discriminated well, but misclassification also occurs, such as between carbonates $\left(\mathrm{CaMgCO}_{3}\right)$ and river sand $\left(\mathrm{SiO}_{2}\right)$.

The differences in the accuracy of the various classification attempts are summarized in Table 1 and 2. Classification results increase significantly, when instead of using TM image (54.3\%), only the texture bands (as contained in stacked images TM-GLCM and TM-GEO) are used for classification (64.5\% and 64.84\% accuracy, respectively). A slight improvement was achieved when newly created images PCA-GLCM and PCA-GEO were used for classification (accuracy of $66.8 \%$ each) compared to the original PCA image without textural bands $(64.45 \%)$. The accuracy level for normal TM bands can thus be increased significantly by incorporating textural -feature bands, while for PCA and PCA composites the increase, is insignificant- however, the initial classification accuracy from PCA containing composites is already much higher than that of normal TM band alone. 


\section{Table 1:}

Classification accuracy of the different TM and PC based composites and composites incorporating textural parameters

\begin{tabular}{|c|c|c|c|c|c|c|}
\hline Classified & TM & PCA & PCA-GLCM & PCA-GEO & TM-GLCM & TM-GEO \\
Images & $(1)$ & $(2)$ & $(3)$ & $(4)$ & $64 \%$ \\
\hline Accuracy & $54.3 \%$ & $64.45 \%$ & $66.8 \%$ & $66.8 \%$ & $64.84 \%$ \\
\hline Kappa & 0.4622 & 0.5957 & 0.65 & 0.6499 & 0.6191 \\
\hline
\end{tabular}

\section{Table 2:}

Classification accuracy of different lithological units based on multispectral TM data ( 6 bands) and TM-PCA data (6 PCs).

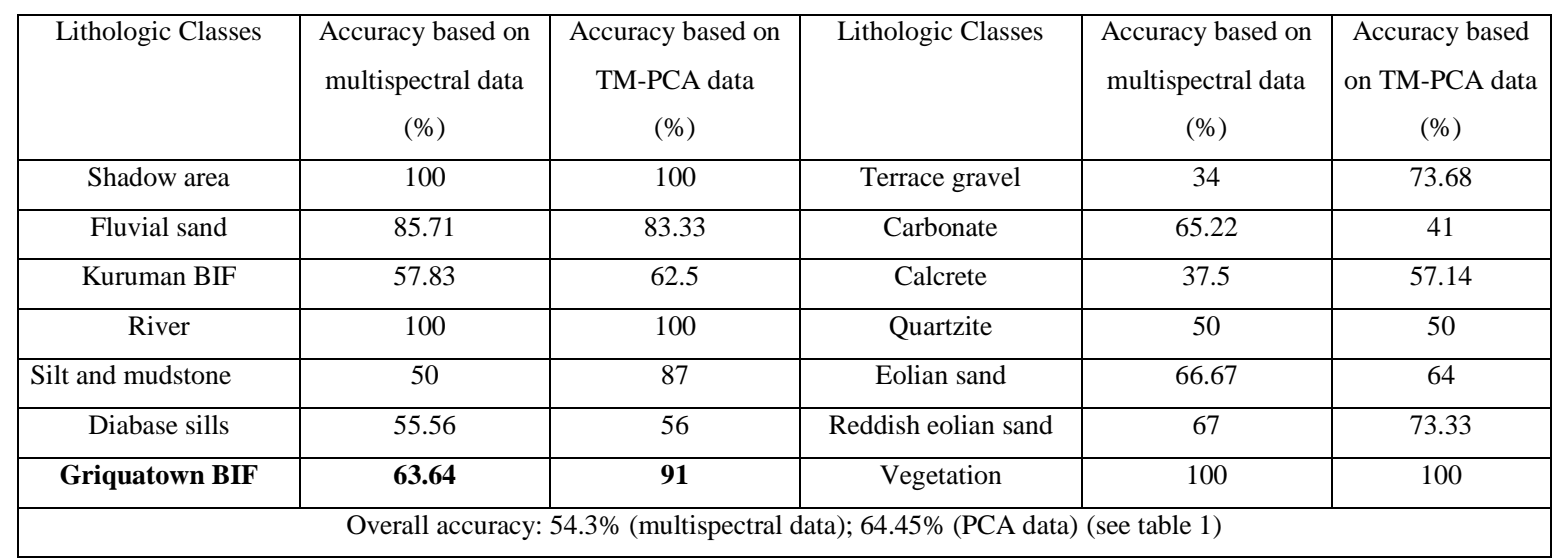




\subsection{Knowledge-based system classification (KBS)}

Based on the procedure described in Section 4.2., from the six images in Table 1, two classified images must be selected for comparison and KBS based classification. Many factors should be considered for the image selection. In chapter 5.1. it could be shown, that the incorporation of textural features can indeed improve classification accuracy, so images (3)-(6) in Table 1, combining textural features, have the priority to be selected. Secondly, since the TM multispectral image and the PCA image (Fig. 2a, b) highlight different aspects of the spectral signature of the rocks, both images combined, complement each other for the best differentiation of the various lithological units. Therefore, images (3) and (4), combining TM image and textural features, belong to one group and the images (5) and (6), combining PCA image and textural features, belong to another group. Two images need to be selected out from these two groups individually. In the latter group, image (6) TM-GEO which incorporates geostatistic features, is given priority because of the relatively higher accuracy of classification. In the former group, the two results have similar accuracy. But the geostatistic features of image (4) PCA-GEO contained some of the same geostatistic bands as image (6) TM-GEO. To ensure maximum difference between selected classification results, image (3), PCA-GLCM was selected for the comparison and for the input into the KBS, together with image (6) TM-GEO.

When interpreting the accuracy tables (Table 1 and 2) resulting from the comparison between classified PCA image and the reference map, it is found that the percentage of correctly classified pixels in the rock type of G-BIF is especially high, with $91 \%$, compared to the TM multispectral image, where it is $64 \%$. That is to say, the G-BIF can be recognized and distinguished well in PCA image and this superiority of the PCA image for G-BIF will be 


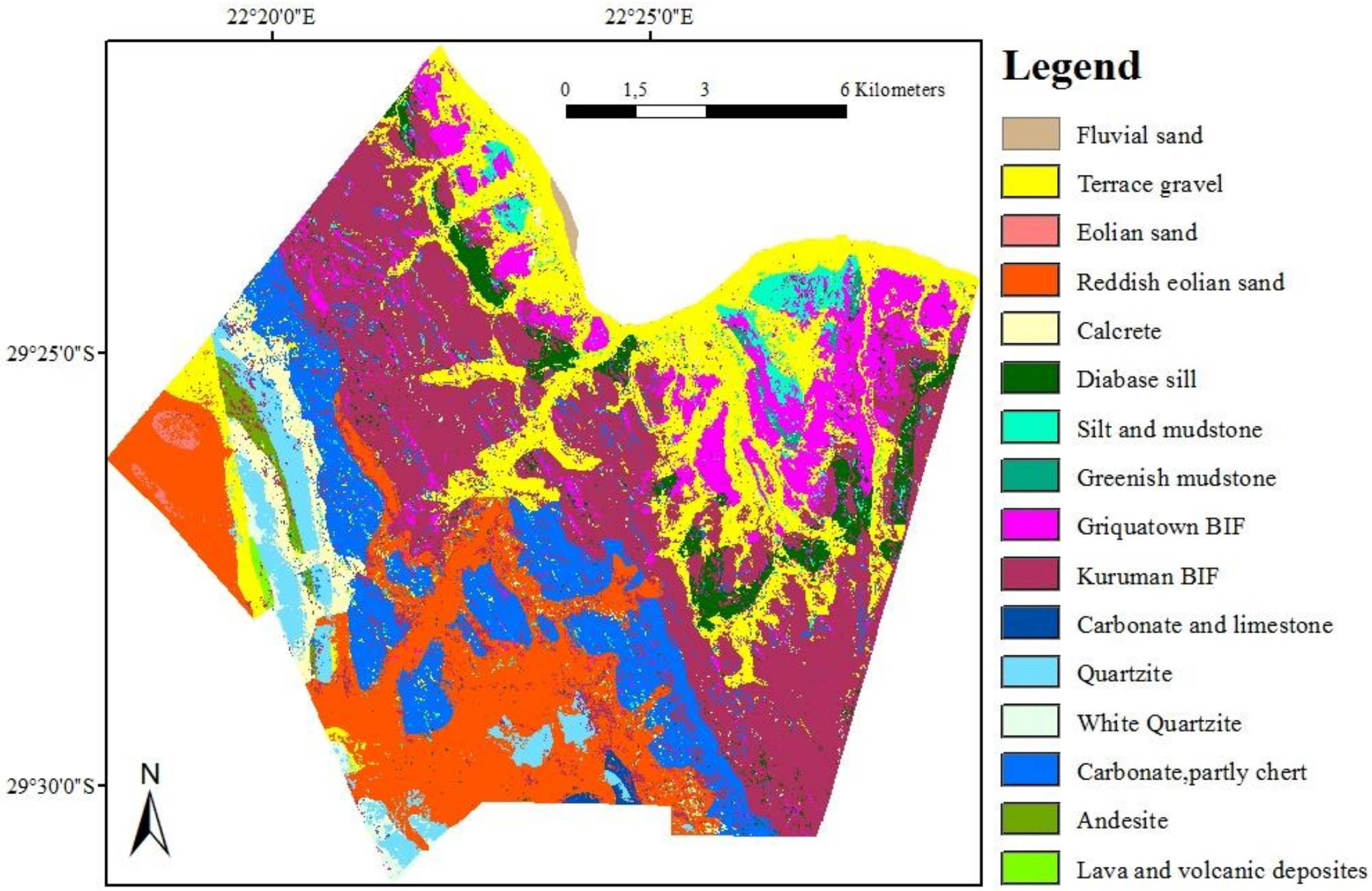

Fig. 6: Final Knowledge- Based System (KBS) classification result based on user defined Maximum-Liklihood Classification (MLC) and the integration of geological map data. 
adopted in KBS. In the algorithm, the class value representing G-BIF is kept unchanged, no matter whether or not the covered pixels are inconsistent.

To a large extent, the percentage of misclassified pixels decreases as soon as the inconsistent pixel values are replaced with the ID value in geological map. Besides, unclassified pixels and shadow covered pixels can be given a specific class value according to the geological map.

As a final step, the accuracy of the final classified image (Fig. 6) is assessed by using the detailed geological map of the test area, at a scale of 1:25000 (Glas, 2008). The overall accuracy is $83.2 \%$ and the Kappa coefficient is 0.7965 , meeting the quality requirements for subsequent lithological mapping.

The information gained by the sensors only reflects the surface condition of the objects, and may often conceal the reality, such as in the case of the greenish parts and the orange colour part in of the BIF (in Figure 2, a). The green colour may result from the mineralogical composition but may equally be caused by differences in the vegetation coverage. The orange colour may result from the high reflectance of silica. Thus, the field check for details is indispensable, even though remote sensing is superior in obtaining a fast overview of a large area.

\section{Conclusions and Outlook}

In the arid test area bordering the southern bank of the Orange River, in Griqualand West, South Africa, multispectral TM bands and respective PCA bands, were combined with textural feature bands to create multi-layer images. These were classified using MLC, and then compared and reclassified in KBS, with the help of a digital geological map at a scale of 1:250000. 
The resulting classified thematic image combines the advantages of the TM multispectral image and the PCA image, spectral features and textural features, allowing for the discrimination of different rock types with high accuracy.

Even though the accuracy was improved considerably after the KBS classification, the traditional MLC accuracy for both, multispectral image and PCA image, was not satisfactory. This is even the case when the texture information is combined in the images, because of the coarse spatial resolution of TM data and the spectral similarity between different rock types.

Thus, misclassification can not be avoided if only the texture features are used. Nevertheless, the results demonstrate that textural features of the lithology can become useful assistant information when they are combined with spectral features. The method used herein is expected to contribute to the generation of a detailed lithological map in the study area of the southwestern Prieska sub-basin in South Africa, especially under the conditions of limited data source and field work possibility, when for example, only TM image and a general geological map on a large scale are available. Further more, using the herein introduced method, geological maps can be updated more easily by implementing the information gained from recent satellite images and advanced image processing methods.

To improve the MLC accuracy, an artificial neural network (ANN) could be designed in the future, for the classification employing the texture features, spectral features and principle components as input. Generally speaking, the more features are included in the ANN, the higher classification accuracy can be achieved. Additionally, DEM, geophysical and geochemical data can also be considered as ancillary data sets to assist classification in KBS. However, such data must be incorporated into a GIS, which is difficult because of the punctual character of geochemical data (sampling problem). These ideas will be further developed in future research. 


\section{Acknowledgements}

The authors are grateful to the China Scholarship Council (CSC) and to the LMU International Office for supporting Li's doctoral research at the Ludwig-Maximilians University München. The University of Pretoria and farmers in Griqualand West, South Africa, especially the family of Jan and Sybil Visagie, made the ground check in South Africa very amiable.

Thanks to the reviewers for their extremely constructive work.

\section{References}

Alaaddin, Y., 2008. Using ASTER Imagery in Land use/cover Classification of Eastern Mediterranean Landscapes According to CORINE Land Cover Project. Sensor 8, 1237-1251.

Altermann, W. and Hälbich, I.W., 1990. Thrusting, folding and stratigraphy of the Ghaap Group along the southwestern margin of the Kaapvaal Craton. S. Afr. J. Geol. 93, 553-556.

Altermann, W. and Hälbich, I.W., 1991. Structural history of the south-western corner of the Kaapvaal Craton and the adjacent Namaqua realm: New observations and reappraisal. Precambrian Research, 52, 133-166.

Altermann, W., 1996. Discussion of zircon Pb-evaporation age determinations of the Oak Tree Formation, Chuniespoort Group, Transvaal Sequence: implications for the Transvaal - Griqualand West basin correlations. S. Afr. J. Geol., 99/3, 337-338.

Altermann, W., 1997. Sedimentological Evaluation of Pb-Zn Potential of the Precambrian Griquatown Fault Zone in the Northern Cape Province, South Africa- Mineralium Deposita, 32/4, 382-391.

Altermann, W. and Nelson, D.R., 1998. Sedimentation rates, basin analysis and regional correlations of three Neoarchaean and Palaeoproterozoic sub- basins of the Kaapvaal craton as inferred from precise U-Pb zircon ages from volcaniclastic sediments. Sediment. Geol., 120, 225-256.

Beukes, N.J., 1986. The Transvaal Sequence in Griqualand West. In: Anhaeusser, C. R. and Maske, S. (Eds.), Mineral Deposits of Southern Africa, Volume 1. Geol. Soc. S. Afr., 819-828.

Chavez, P.S J., Guptill, C. and Bowel, J.A., 1984. Image processing techniques for Thematic Mapper data. In: proceeding of the American Society of Photogrametry Conference, 728-752. 
Council for Geosciences, 1995. Geological Map of South Africa 1:250000, Sheet 2922 Prieska, Geological Survey of South Africa, Pretoria.

Chen, D., Stow, D.A. and Gong, P., 2004. Examining the effect of spatial resolution and texture window size on classification accuracy: an urban environment case. Int. J. Remote Sens. 25/11, 2177-2192.

Chica-Olmo, M. and Abarca-Hernandez, F., 2000. Computing geostatistical image texture for remotely sensed data classification. Computers \& Geoscience 26, 373-383.

Congalton, R. 1991. A review of assessing the accuracy of classification of remotely sensed data. Remote Sensing of Environment 37, 35-46.

Daniels, A.E., 2006. Incorporating domain knowledge and spatial relationship into land cover classifications: A Rule-based approach. Int. J. Remote Sens. 27/14, 2949-2975.

Eriksson, P.G., Altermann, W. and Hartzer, F.J., 2006. The Transvaal Supergroup and precursors. Chapter 10 In: Johnson, MR., Annhaeusser, CR. Thomas, RJ. (Editors): The Geology of South Africa. Geol. Society of South Africa, 237-260.

Frei, M. and Altermann, W., 2006. Synergetic remote sensing applications to address geoscientific problems in Africa. 21st CAG, Maputo, Mozambique, 3-6 July, 2006. Abstracts, 472-473.

Glas, K., 2008. Fernerkundung und Geoinformationssysteme zur geologischen Kartenerstellung, unpublished BSc thesis, Ludwig Maximilians University of Munich, 72pp.

Haralick, R.M., 1979. Statistical and structural approaches to texture. Proceeding of the TEEE, 67, 786-804.

Jakomulska, A.M., and Stawiecka, M.N., 2002. Integrating spectral and textural information for land cover mapping. In: G. Begni (Editor): Observing our Environment from Space- New solutions for a New Millennium, Swets \& Zeitlinger, Lisse, The Netherlands, 347-354.

Kaufman, Y.J. and Sendra, C., 1988. Algorithm for automatic atmospheric corrections to visible and near-IR satellite imagery. Int. J. Remote Sens. 9, 1357-1381.

Kavzoglu, T. and Mather, P.M., 2003. The Use of Backpropagating Artificial Networks in Land Cover Classification. Int. J. Remote Sens. 24, 4907-4938.

Leica Geosystems, ERDAS Field Guide (7th edition), 2003. GIS \& Mapping, LLC, Atlanta, Georgia, 698pp.

Li, N., Frei, M., Altermann, W. 2009. Improvement on lithologic classification of remote sensing data using knowledge-based classifier in southwestern Prieska sub-basin, Transvaal Supergroup, South Africa. Publikationen der Deutschen Gesellschaft für Photogrammetrie, Fernerkundung und Geoinformation e.V., DGPF Tagungsband 18 / 2009, 191-200 
Lloyd, C. D., Berberoglu, S., Curran, P. J. and Atkinson, P. M., 2003. A comparison of texture measures for the per-field classification of Mediterranean land cover. Int. J. Remote Sens. 25/19, 3943-3965.

Loughlin, W. P., 1991. Principal Component Analysis for Alteration Mapping. Photogrammetric Engineering and Remote Sensing 57, 1163-1169.

Lu, D. and Weng, Q., 2006. A survey of image classification methods and techniques for improving classification performance. Int. J. Remote Sens. 28/5, 823-870.

Rao, P.V.N., Sai, M.V.R.S., Sreenivas, K., Rao, M.V.K., Rao, B.R M., Dwivedi, R.S. and Venkataratnam, L., 2002. Textural analysis of IRS-1D panchromatic data for land cover classification. Int. J. Remote Sens. 23/17, 3327-3345.

Shaban, M.A. and Dikshit, O., 2001. Improvement of classification in urban areas by the use of textural features: The case study of Lucknow city, Uttar Pradesh. Int. J. Remote Sens. 22/4, 565-593.

Shalan, M.A., Arora, M.K. and Ghosh, S.K., 2003. An evaluation of fuzzy classifications from IRS image: a case study. Int. J. Remote Sens. 24, 3177-3186.

Stefanov, W.L., 2001. Monitoring urban land cover change: An expert approach to land cover classification of semiarid to arid urban centers. Remote Sensing of Environment 77, 173-185.

Visser, J.N.J., 1989. The Permo-Carboniferous Dwyka Formation of Southern Africa: deposition by a predominantly subpolar marine ice sheet. Palaeogeogr., Palaeoclimatol., Palaeoecol. 70, 377-391.

Walraven, F. and Martini, J., 1995. Zircon Pb-evaporation age determinations of the Oak Tree Formation, Chuniespoort Group, Transvaal Sequence: Implications for Transvaal Griqualand West basin correlations. S. Afr. J. Geol. 98, 58-67.

Zhang, C., Franklin, S.E. and Wulder, M.A., 2003. Geostatistical and textural analysis of airborne-acquired images used in forest classification. Int. J. Remote Sens. 25/4, 859-865. 